\title{
Experimental Investigation of the Effect of Temperature on the Structures in the Measurement of Displacements
}

\author{
Boštjan KOVAČIČ, Nenad GUBELJAK, Samo LUBEJ
}

\begin{abstract}
Measurement of displacement and deformation of structures is a very demanding engineering task and is carried out on all existing and newly built bridges and other demanding structures. The results of the measured displacements are thus influenced by several atmospheric parameters, among which the temperature is exposed, since the measurements are usually carried out over the whole day at different seasons and conditions, where the temperature differences are significant. In this paper the influence of temperature on the geodetic measurements of the displacements of the steel structure in the unburdened state is presented. To this end, measurements of the steel bridge during the summer time were performed. The temperature and thermal imaging at various locations every half hour were investigated. To calculate the influence of the temperature on the position of the observed point some statistical methods were used. It is evident from the results that in this kind of geodetic measurements, temperature measurements are indispensable. By taking into account the temperature correction results that are very comparable with the predicted values of displacements which can be obtained. Not observing the temperature can result in misleading values of displacement which can lead to misinterpretation and consideration of the obtained value.
\end{abstract}

Keywords: accuracy; statistics; structures; surveying; temperature gradient

\section{INTRODUCTION}

In engineering, displacement measurement and consequently deformation determination should be performed very accurately. The construction practice in deformation measurements on bridges shows the importance of vertical deformations because these measurements determine the structural bending, which is the relevant physical quantity to determine load-bearing capacity and safety. If dynamic responses are measured, the relevant deformations appear in all three orthogonal directions; therefore the measurement set MinimatePlus for instantel vibration monitors is used. In addition, geodetic instruments and methods are used for determination of displacements in all directions and their speed. Vertical displacements are determined by geodetic methods, and also measurement results can provide values to determine horizontal displacements and deformation speed. Lately, robot electronic tachometers are mostly used in practice because they allow for automatic prism monitoring with very accurate results.

Methods for determining displacements and deformations of objects have become a constant in engineering geodesy. Geodetic measurements of deformations in the broad sense include all measurements for determining the change of the shape of the building or the ground under the influence of external and internal forces. The development of deformation measurement can be monitored over long time period. Precise geodetic measurements prevailed in the 1960s, but the assessment of accuracy was uncertain. The rule was that the points outside the deformation area were considered as stable [1]. In the next decade, the development of measurement equipment, which enabled the measurement of increased accuracy, and the development of computer equipment and programs enable to do adjustments as described by [2-8]. The emphasis there was in a priori stable points and on a geodetic date. However, the result of this research is that all the points of the basic geodetic network are considered as unknown and unstable, which led to the development of deformation analysis as described in [9-13].
Obviously, a major development of measurement instruments in the last decade today provides extremely reliable results of high accuracy and enables short and long-term monitoring of objects in terms of observation of displacements and consequently deformations. In addition to high accuracy instruments, the parameters that influence the results at movement measuring also should be taken into account.

In fact, the load capacity of most structures should be checked in the form of a load test prior to use. Different methods and instruments depending on the complexity of the structure can be used. In general, the construction is investigated under a static and dynamic load during load test. Absolute and relative methods depending on the complexity of construction, accessibility and height of the construction are used for static testing. Most frequently, geodetic methods, such as trigonometric heliometry, levelling and GNSS methods are used among absolute methods. Recently, with the development of the measurement technique, the geodetic methods began to be used also for tests of the dynamic properties of structures. The results of geodetic measurements are extremely important and must therefore be reliable and accurate when determining displacements and deformations. On one hand, the equipment meets these criteria but on the other hand, the measurements are subject to field and meteorological conditions, which can greatly distort the results. Thus, analysis of the results in the form of deformation analysis and statistical methods is very important [14].

The article focuses on the influence of meteorological changes, especially on temperature and geodetic measurement results, because the temperature is one of the parameters that impact the results most. Geodetic measurements of vertical displacements were carried out by Leica RTS TS50 robot total station. Every hour on the hour, the temperature measurements were taken on objective and instrument casing as well as on the steel structure, prism glass and retro tape target. Temperature measurements were taken by a wired probe of the TESTO 435-1 measuring instrument, while the pressure and 
relative humidity were measured by the multifunction probe of the device. In order to determine the influence of meteorological parameters on measurement results gained by the RTS Leica TS50, the control shooting was performed by the Flir T250 thermal camera.

\section{ERRORS AND ASSESSMENT OF THE ACCURACY OF GEODETIC MEASUREMENTS}

In terms of geodetic measurements within various engineering works, the expectations of the client on the one hand and surveyors on the other hand may differ a lot. Quality measurements might not be the most accurate ones, but those whose result is in accordance with expectations or the measurement theory. Moreover, precision measures for engineering measurements should also be taken into account. These are those quantities that further explain the measurement results. Usually the measurement result itself does not provide data on the quality of the measurement, therefore we try to explain the result of the measurement with different additional quantities. In geodesy deviations, empirical standard deviation and standard deviation of mean values is usually used [15]:

- deviation, variance: $\sigma_{x}^{2}$ is defined as the average square deviation of the measurement values $x_{i}$ from the expected value $\mu_{x}$ :

$$
\sigma_{x}^{2}=\sum_{i=1}^{n}\left(x_{i}-\mu_{x}\right)^{2}
$$

- the estimated value for the unknown variance $\sigma_{x}^{2}$ is an empirical variance:

$s_{x}^{2}=\frac{1}{n-1} \sum_{i=1}^{n}\left(x_{i}-\bar{x}\right)^{2}=\frac{1}{n-1} \sum_{i=1}^{n} v_{i}^{2}$.

When we increase the number of measurements $n$, which is necessary in geodesy, then $\bar{x}$ converge against $\mu_{x}$ and $s_{x}^{2}$ toward $\sigma_{x}^{2}$. For practical use, the variance such as a dispersion measure is less suitable. When we determine the dispersion of the measurement values $x_{i}$ of some measurement series, we calculate the empirical standard deviation $s_{x}$ as:

$s_{x}=+\sqrt{\frac{1}{n-1} \sum_{i=1}^{n}\left(x_{i}-\bar{x}\right)^{2}}$.

An important quantity to assess the quality of mean values in geodetic measurements is the standard deviation of mean values $\bar{x}$, which is calculated as:

$$
\text { For } n \rightarrow \alpha \sigma_{\bar{x}}=\frac{\sigma_{x}}{\sqrt{n}} \text { and for } n \text { measurements of }
$$

measurement series $s_{\bar{x}}=\frac{s_{x}}{\sqrt{n}}$.

From this equation, we can conclude that increase in the number of measurements leads to reduction in the size of the standard deviation of mean value [16].
In order to better evaluate our measurements, we need to know the confidence interval. By definition, the interval is called the confidence interval for an unknown value of the measured quantities, which overlaps this value with the prescribed and pre-set value. In geodetic measurements, the confidence interval for the true value of $\bar{x}$ plays an important role. It is defined as the interval $C=\left[C_{\mathrm{zg}}, C_{\mathrm{sp}}\right]$, containing the true value with the specified value $1-\alpha$ :

$P=\left\{C_{\mathrm{sp}} \leq \bar{X} \leq C_{\mathrm{zg}}\right\}=1-\alpha$

The boundaries of $C_{\mathrm{sp}}$ and $\mathrm{C}_{\mathrm{zg}}$ are calculated as a function of statistical probability and distribution. Interval boundaries are calculated using:

$$
\begin{aligned}
& C_{\mathrm{sp}}=\bar{X}-k_{1-\alpha / 2} \cdot \sigma_{\bar{x}} \\
& C_{\mathrm{zg}}=\bar{X}+k_{1-\alpha / 2} \cdot \sigma_{\bar{x}}
\end{aligned}
$$

Where is: $X$ - the estimated value for the true value of $x$, $k_{1-\alpha / 2} \ldots$ quantile of normal distribution $N(0,1)$

The eq. (4) can be written as:

$$
P=\left\{\bar{x}-k_{1-\alpha / 2} \cdot \sigma_{\bar{x}} \leq \tilde{X} \leq \bar{x}+k_{1-\alpha / 2} \cdot \sigma_{\bar{x}}\right\}=1-\alpha
$$

In geodesy, the international conventional confidence interval is $95 \%(\alpha=5 \%=0.05$; unless otherwise agreed) [14]. Based on the false probability of $5 \%$, the quantile normal distribution is determined as $Z_{0,975}=1,96$. The larger the statistical security is selected, the wider the confidence interval (Tab. 1).

Table 1 Quantile of normal distribution for different confidence intervals

\begin{tabular}{|c|c|c|c|c|c|c|c|}
\hline$P$ & $68,3 \%$ & $90 \%$ & $95 \%$ & $95,4 \%$ & $99 \%$ & $99,7 \%$ & $99,9 \%$ \\
\hline$k-\alpha / 2$ & 1,00 & 1,64 & 1,96 & 2,00 & 2,58 & 3,00 & 3,30 \\
\hline
\end{tabular}

\subsection{Measurement and Methods of Calculating the Temperature of the Structure}

It is important to note that under the influence of temperature the displacement of the point can also occur. Determining the temperature of the structure is a very demanding process. The parts of the structure are exposed to various external influences according to the geographical position. While determining the displacement of the structure, some parts are on the sun side, and therefore warmer, some parts are in the shades and therefore colder.

This creates temperature differences between the individual structure profiles as well as between the points between the profiles. Standing points for monitoring are predetermined and it would be normal to continuously measure the temperature of the air and the material as well as the temperature at the standpoint of the instrument. Unfortunately, in practice, due to the inaccessibility to the measurement points, the temperature cannot be measured at these desired locations [17].

Even with the elimination of all meteorological parameters, we find that there is still a difference in the results of measured values. This error is caused by the temperature influence on the stretching of the structure. Thus, temperature should be measured on the structure 
with elongations or shrinkage consideration. The temperature can be determined in two ways:

\section{Indirect, computed}

- $\quad$ Direct with the measurement on the structure.

Indirect or calculated structural temperature is obtained on the basis of the equation [18]:

$$
\begin{aligned}
& t=0,28 \cdot t_{21}^{i-2}+0,037 \cdot\left(t_{7}^{i-1}+t_{21}^{i}\right)+ \\
& +0,146 \cdot\left(t_{14}^{i-1}+t_{14}^{i}\right)+0,146 \cdot\left(t_{21}^{i-1}+t_{7}^{i}\right)
\end{aligned}
$$

or by [19]:

$$
t=1,14 \cdot t_{\max }-4,5^{\circ}
$$

Where is: $t_{21}^{i-2}$ air temperature at $9 \mathrm{pm}$ two days before measurement; $t_{14}^{i-1}$ air temperature at $2 \mathrm{pm}$ one day before measurement; $t_{21}^{i-1}$ air temperature at $9 \mathrm{pm}$ one day before measurement; $t_{7,14,21}$ temperature at $7 \mathrm{am}, 2 \mathrm{pm}$ and $9 \mathrm{pm}$ on the day of measurement; $t_{\max }$ maximal temperature on the day of measurement.

Immediately the temperature is measured with the sensors on the structure in cooperation with the designer, who determines the measurement sites. The sensors are connected to the measurement equipment, so that the temperature data for each geodetic measurement can be obtained separately and simultaneously with other geodetic measurements. This method is also more reliable and simpler than manual measurement of temperature; and temperature corrections can be obtained separately for each measurement.

\section{EXAMPLE OF DETERMINATION OF THE TEMPERATURE DEPENDENCE AND VERTICAL DISPLACEMENT}

The measurement of the steel rail bridge was performed in the summer time under extreme temperatures. The temperature was measured with a contact probe on the total station eyepiece, on a glass prism on the bridge, on a self-adhesive retro target, and directly on a structure near geophone. In addition, readings were taken for the temperature of the air at the total station and the temperature below the bridge in the shadow, air pressure and humidity at the instrument and under the bridge. Thermoscale photo shooting of the bridge was performed near the measured targets. From all measurements, the vertical component between the instrument and the targets and between the checkpoint and the targets was calculated. Geodetic measurement was performed using the Leica TS50 instrument on four geodetic points G1-n and G2-n (Figs. 1, 2 and 3). In order to determine displacements, the geodetic device Leica RTS50 was used, which represents the new generation of electronic tachometers (RTS). The Leica TS50 is capable of sampling space information with the frequency up to 10 $\mathrm{Hz}$; however, the frequency is increased to 30 readings per second with the help of additional programme equipment, which controls the instrument and uses GeoCOM protocol. The programme equipment for monitoring the dynamic target with the reading speed in milliseconds was developed at University of Zagreb, Faculty of geodesy, and it is connected to the instrument through the GEV269 cable. RTS is controlled via the GeoCOM/ZG programme, which can read the length, angles and time or angles and time only. Importantly, switching off the distance meter allows for more constant angle readings, which is essential for further analyses and calculations of dynamic response.

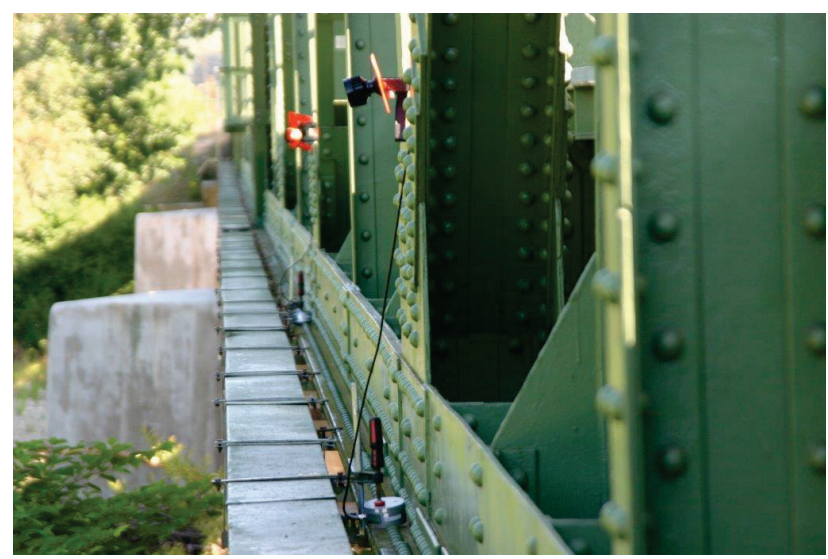

Figure 1 Position of geodetic points and geofon

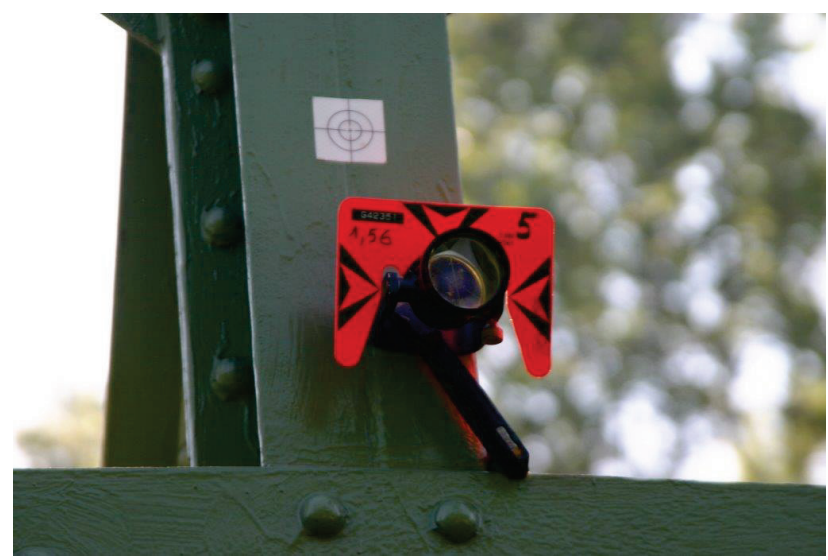

Figure 2 Geodetic point G2-1 - the prism and G2-3 retro tape target

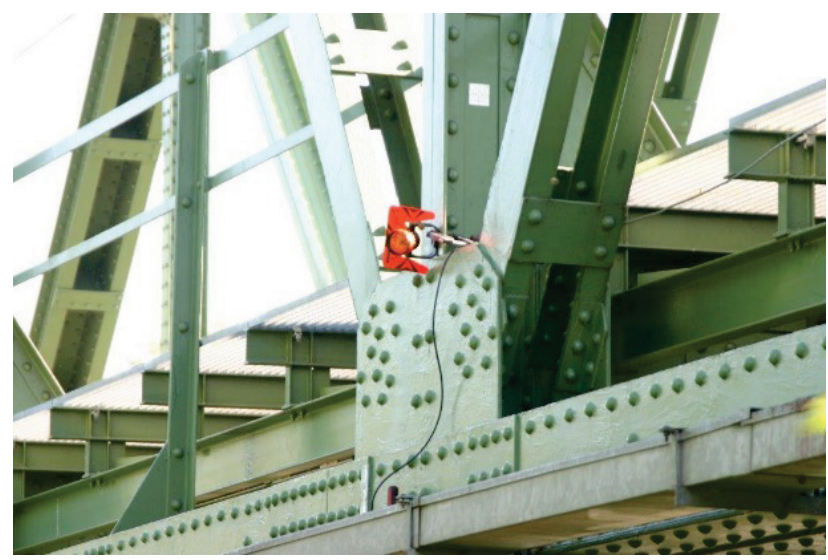

Figure 3 Geodetic point G1-1 - the prism and G1-3 retro tape target

In addition to the geodetic points, the Instantel geophone was installed, which monitored the motion of the object in all three axes, both burdened and unburdened. Geodetic points were observed at 7, 8, 9, 9: 30, 10, 10:30 and $11 \mathrm{am}$. The measurements were carried out in two instrument faces and five series sets. This paper presents a balanced average value of the vertical component only. 


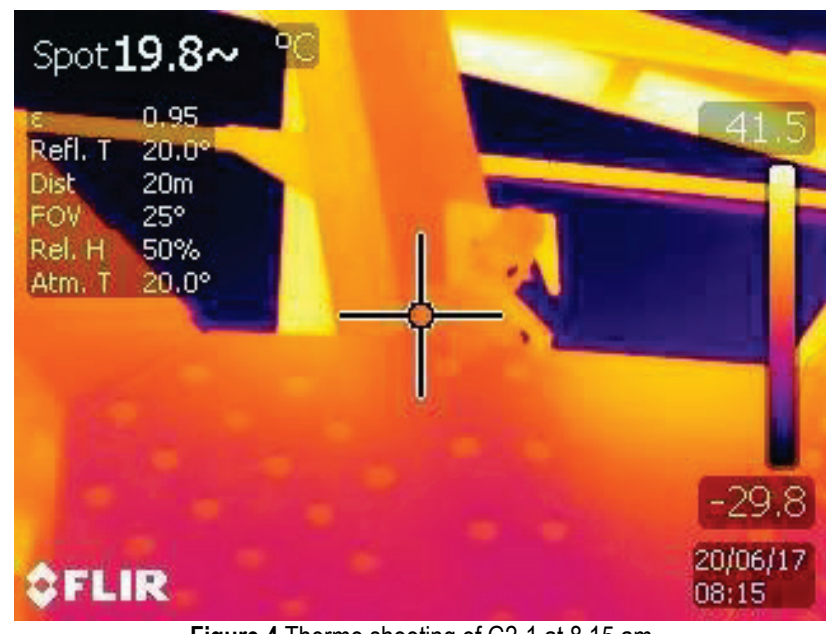

Figure 4 Thermo shooting of G2-1 at 8.15 am

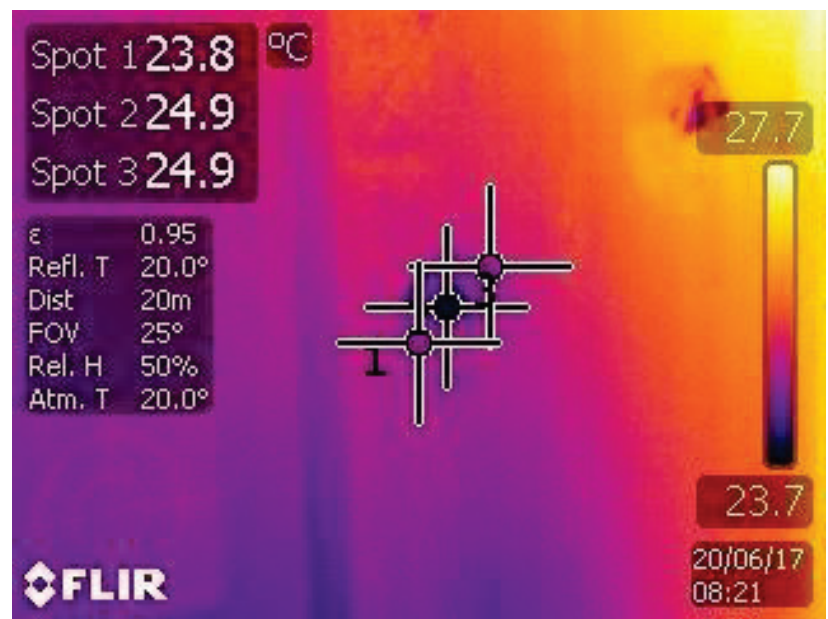

Figure 5 Thermo shooting of G2-1, G2-2 and G2-3 at 8.15 am

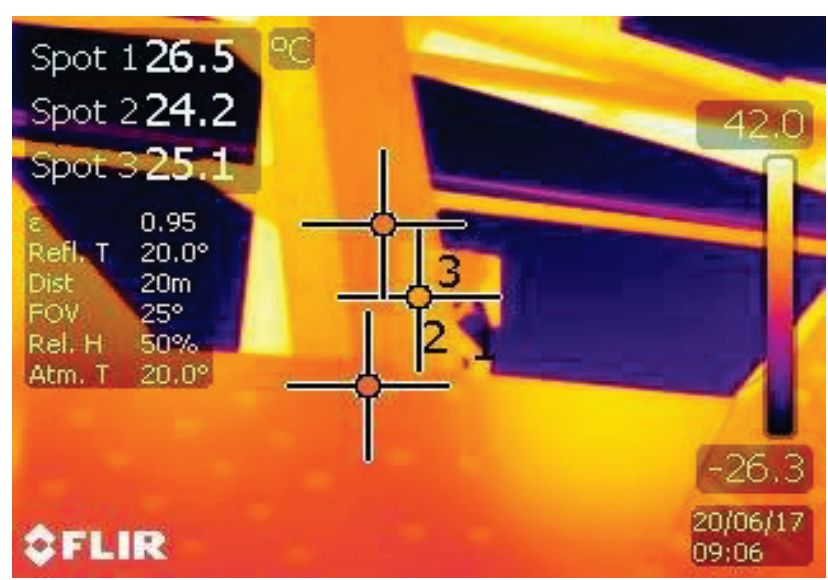

Figure 6 Thermo picture of points G2-1, G2-2 and G2-3 at 9:06 am

Such research demands top equipment, which needs to be calibrated in order to ensure reliable and accurate results. Geodetic measurements were performed by the Leica TS50 robot total station with the angle accuracy of 0.5 ", while the temperature measurements were taken by the usage of the TESTO 435-1 multifunctional measuring instrument which promised the accuracy of the measured temperatures $\pm 0.2^{\circ} \mathrm{C}$ and by the Flir T250 thermal camera, which enabled accuracy of the temperature readings \pm 0.08 ${ }^{\circ} \mathrm{C}$. The temperature measurements obtained by the probe in ${ }^{\circ} \mathrm{C}$, humidity in $\%$ and air pressure in mbar are shown in Tab. 2.
Figs. 4-8 show the results of the thermo-image shooting at the observed points.

Moreover, the temperature difference between the structure and the geodetic point can be seen from Fig. 4 and 5. At this point the temperature of $20.7{ }^{\circ} \mathrm{C}$ was obtained with a contact probe, which can also be estimated roughly from the colour scale. Further, Figs. 6, 7 and 8 show the thermal images at different times and places. All Figures display a great temperature difference between the parts of the construction and the geodetic targets and the uneven distribution of the temperature by parts of the structure.

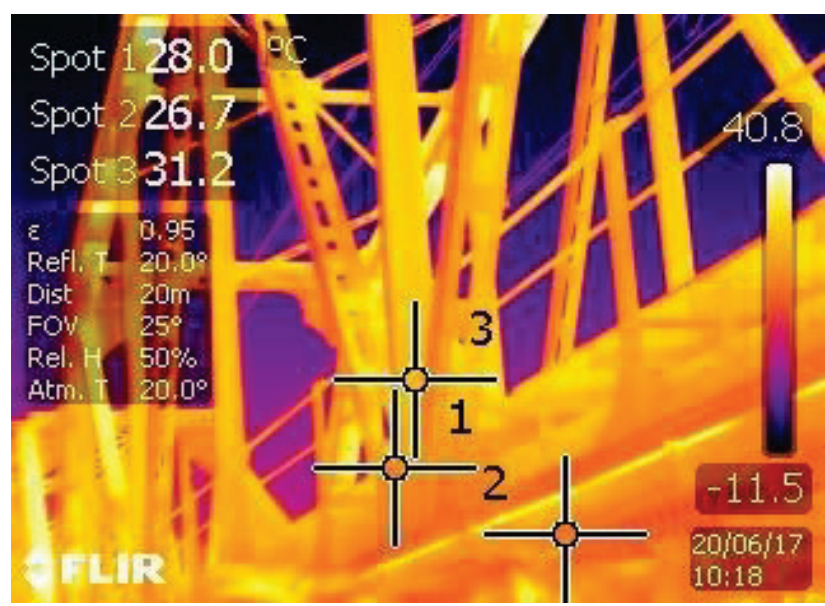

Figure 7 Thermo picture of points G1-1, G1-2 and 1-3 at 10:18 am

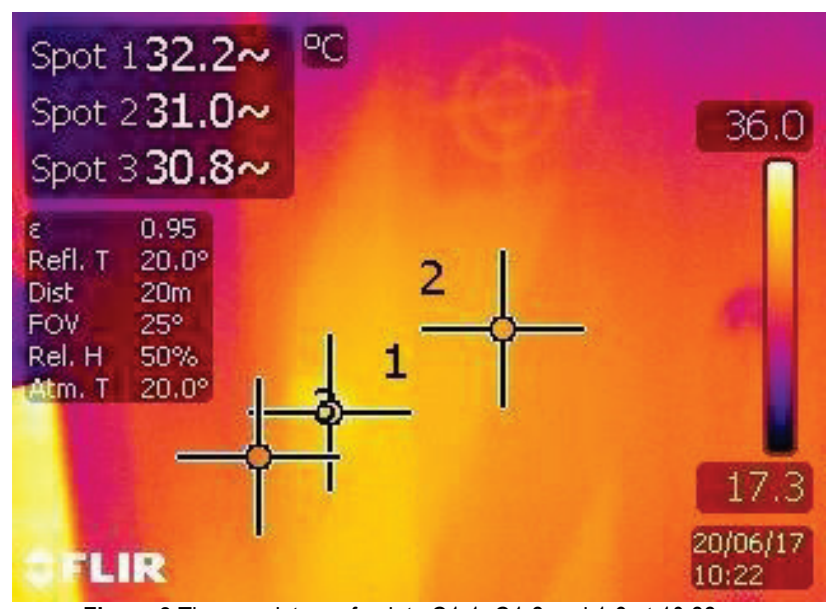

Figure 8 Thermo picture of points G1-1, G1-2 and 1-3 at 10:22 am

Geodetic measured height differences in $m$ between stand point S1 and points G1-n and G2-n and control point S2 and points G1-n and G2-n can be seen in Tab. 3 .

Calculated accuracy in the form of standard deviation and standard deviation of mean values are shown in Tab. 4. They are calculated using the equations (Eq. (2) and (3)). On the basis of these values, the measurements were carried out with an average accuracy of $0.884 \mathrm{~mm}$. The average standard deviation of mean values was $0.0313 \mathrm{~mm}$.

The reason for the occurrence of differences in standard deviations of observed points in different time periods is the influence of different temperatures during measurements. 


\subsection{Statistical Determination of Correlation between Measured Values}

Statistical analysis for measurement results of temperature, pressure and humidity considers the gained values from
Tab. 2. In addition, Tab. 3 shows geodetically determined height differences, which were taken into account in the process of correlation determination between measured values.

Table 2 Measured temperature with the probe in ${ }^{\circ} \mathrm{C}$, humidity in $\%$ and air pressure in mbar

\begin{tabular}{|c|c|c|c|c|c|c|c|c|c|c|c|c|}
\hline Time & $\begin{array}{c}T_{\text {air }} \\
\text { Under the } \\
\text { bridge } \\
\end{array}$ & $\begin{array}{c}\phi_{\text {air }}(\%) \\
\text { Under the bridge }\end{array}$ & $\begin{array}{c}T_{\mathrm{G} 1-1} \\
\text { on the point } \mathrm{G} \\
1-1\end{array}$ & $\begin{array}{c}T_{\mathrm{G} 1-2} \\
\text { on the point } \mathrm{G} \\
1-2 \\
\end{array}$ & $\begin{array}{c}T_{\mathrm{G} 1-3} \\
\text { on the point } \mathrm{G} \\
1-3 \\
\end{array}$ & $\begin{array}{c}T_{\mathrm{G} 2-1} \\
\text { on the point } \mathrm{G} \\
2-1 \\
\end{array}$ & $\begin{array}{c}T_{\mathrm{G} 2-2} \\
\text { on the point } \mathrm{G} \\
2-2 \\
\end{array}$ & $\begin{array}{c}T_{\mathrm{G} 2-3} \\
\text { on the point } \mathrm{G} \\
2-3 \\
\end{array}$ & $T_{\text {air on instr }}$ & $\begin{array}{c}T_{\text {air near the }} \\
\text { instr }\end{array}$ & $\begin{array}{c}\phi_{\text {air }}(\%) \\
\text { near the instr }\end{array}$ & $\begin{array}{c}\text { Pressure } \\
\text { (mbar) } \\
\text { near the instr }\end{array}$ \\
\hline $7 \mathrm{am}$ & 17,3 & 84,1 & 18,3 & 18,5 & 18,1 & 19,1 & 19,0 & 19,3 & 25,8 & 23,6 & 55 & 1014 \\
\hline 8 & 18,3 & 82,7 & 19,0 & 19,9 & 19,1 & 20,4 & 20,3 & 20,7 & 27,6 & 25,8 & 53 & 1013 \\
\hline 9 & 24,0 & 52,9 & 23,3 & 24,6 & 23,5 & 24,0 & 23,3 & 24,5 & 28,8 & 27,2 & 53 & 1012 \\
\hline 9.30 & 26,6 & 44,2 & 25,7 & 26,3 & 25,9 & 25,8 & 25,0 & 26,5 & 30,2 & 31,2 & 50 & 1013 \\
\hline 10 & 27,2 & 41,6 & 27,2 & 28,0 & 27,5 & 27,3 & 26,0 & 28,0 & 32,9 & 32,2 & 46 & 1014 \\
\hline 10.30 & 27,9 & 40,0 & 30,1 & 29,9 & 29,7 & 30,1 & 28,5 & 30,0 & 34,6 & 33,0 & 44 & 1013 \\
\hline 11 & 28,3 & 38,8 & 32,6 & 31,2 & 32,9 & 31,4 & 30,3 & 31,4 & 36,0 & 33,5 & 42 & 1012 \\
\hline 12 & 34,1 & 36,3 & 34,1 & 35,2 & 34,2 & 36,2 & 35,7 & 35,9 & 36,6 & 34,5 & 39 & 1011 \\
\hline
\end{tabular}

Table 3 Geodetic measured height differences in $m$ between station point S1 and G1-n in G2-n and control point S2 and points G1-n and G2-n

\begin{tabular}{|c|c|c|c|c|c|c|c|c|}
\hline Time & S1-G1-1 & S1-G1-3 & S1-G2-3 & S1-G2-1 & S2-G1-1 & S2-G1-3 & S2-G2-1 & S2-G2-3 \\
\hline $7 \mathrm{am}$ & 3,4387 & 3,8770 & 3,8760 & 3,7531 & 4,0611 & 4,4995 & 4,1888 & 4,3755 \\
\hline 8 & 3,4389 & 3,8772 & 3,8762 & 3,7532 & 4,0614 & 4,4997 & 4,1890 & 4,3757 \\
\hline 9 & 3,4412 & 3,8786 & 3,8786 & 3,7556 & 4,0635 & 4,5011 & 4,1892 & 4,3781 \\
\hline 9.30 & 3,4410 & 3,8784 & 3,8785 & 3,7558 & 4,0635 & 4,5010 & 4,1891 & 4,3783 \\
\hline 10 & 3,4409 & 3,8783 & 3,8783 & 3,7560 & 4,0634 & 4,5008 & 4,1890 & 4,3785 \\
\hline 10.30 & 3,4407 & 3,8785 & 3,8781 & 3,7558 & 4,0633 & 4,5012 & 4,1891 & 4,3782 \\
\hline 11 & 3,4405 & 3,8784 & 3,8777 & 3,7556 & 4,0630 & 4,5002 & 4,1892 & 4,3781 \\
\hline 12 & 3,4401 & 3,8787 & 3,8781 & 3,7560 & 4,0637 & 4,5013 & 4,1896 & 4,3785 \\
\hline
\end{tabular}

Table 4 Calculated standard deviations and standard deviation of mean values

\begin{tabular}{|c|c|c|}
\hline Point & $S_{\mathrm{x}}(\mathrm{m})$ & $S_{\bar{\chi}}(\mathrm{m})$ \\
\hline G1-1 & 0,000956 & 0,000338 \\
\hline G1-2 & 0,000655 & 0,000231 \\
\hline G1-3 & 0,001019 & 0,000361 \\
\hline G1-4 & 0,001236 & 0,000437 \\
\hline G2-1 & 0,001018 & 0,000359 \\
\hline G2-2 & 0,000705 & 0,000249 \\
\hline G2-3 & 0,000231 & 0,000082 \\
\hline G2-4 & 0,001253 & 0,000443 \\
\hline
\end{tabular}

It is realistic to expect dependence between the temperature and the height of the point or vertical displacement of that point under load, therefore this connection needs to be studied. Thus, it is necessary to define the mathematical model of displacements first in the function of temperature, then to study the stochastic connection and the strength of this connection. Based on the measured temperature and the calculated height difference, the coefficient of correlation of these two variables [20] is calculated using:

$$
r=\sqrt{\frac{\left(\Sigma x y-\frac{\Sigma x \Sigma y}{N}\right)^{2}}{\left(\Sigma x^{2}-\frac{(\Sigma x)^{2}}{N}\right) \cdot\left(\Sigma y^{2}-\frac{(\Sigma y)^{2}}{N}\right)}}
$$

where $N$ - number of pairs of measurement results; $x, y-$ variable.

If $r=0$, the variables are independent, but if $r= \pm 1$, the variables are functionally (linear) dependent. In order to confirm the final conclusions about the power of the connection between the two variables, it is necessary to test the correlation coefficient value as shown in Tab. 5. Since the correlation coefficient is a random variable from a particular sample, it needs to be verified if it is significantly different from zero. Two hypotheses should be tested:

$H_{\mathrm{o}}: r=0$

and alternative hypotheses:

$H_{\mathrm{o}}: r \neq 0$

Testing of these hypotheses can be calculated using:

$t=r \cdot \frac{\sqrt{N-2}}{\sqrt{1-r^{2}}}$

This quantity is distributed by Student's t-distribution with the degree of freedom $k=N-2$. Value $t_{0}$ can be obtained from the table for the $t$ distribution for the $k$ level of characteristics of $5 \%$ degree of freedom. If $t$ is greater than $t_{\mathrm{o}}$ on the statistical very significant correlation can be concluded. Tab. 6 shows the calculated coefficients $t$ for individual cases.

For our example, where the height difference (measured 8 times) was observed, from the table for the $t$ distribution we read for 6 levels of freedom at the $5 \%$ risk the value for $t_{0}: t_{\mathrm{o}}=3,7074$.

The results from Tab. 5 show that the highest coefficient of confidence correlation is at G1-4 which was also the highest point. In addition, it can be concluded that it was also the subject of the highest refraction due to the bigger vertical angle. The highest correlation was noted at this point among all parameter measurements in Table 5. Furthermore, Tab. 6 shows linear increasing of calculated coefficient of confidence correlation at all points and temperatures. As a result, the hypothesis that the change in temperature impacts the measured displacements can be confirmed. 
Based on the calculated values of the correlation coefficient and testing of the correlation confidence, which is shown in Tab. 6, a very high linear dependence between height differences and temperature can be concluded. Consequently, it is logical to take this into account in the final calculations in the shown way. The influence of the temperature is very high in the measurement of steel structures, where further knowledge and consideration of the structural physics is necessary. Since we know that geodetic measurements of displacements are carried out throughout the day and under different conditions and seasons, it is necessary to take into account the impact of meteorological factors during processing of results. Thus, in the mathematical model of the displacements and, consequently, the deformations affected by the temperature should be considered.

Table 5 Calculated coefficients of the correlation

\begin{tabular}{|c|c|c|c|c|c|c|c|c|c|c|c|}
\hline & $\begin{array}{c}T_{\text {under the }} \\
\text { bridge }\end{array}$ & $T_{\text {near the instr }}$ & $T_{\text {on the instr }}$ & $T_{\text {on the G1-3 }}$ & $T_{\text {on the G2-3 }}$ & $T_{\text {on the G1-1 }}$ & $T_{\text {on the G2-1 }}$ & $\begin{array}{c}T_{\text {on the steel }} \\
\text { G1-2 }\end{array}$ & $\begin{array}{c}T_{\text {on the steel }} \\
\text { G2-2 }\end{array}$ & $\begin{array}{c}\phi_{\text {air }}(\%) \text { under } \\
\text { the bridge }\end{array}$ & $\begin{array}{c}\phi_{\text {air }}(\%) \text { near } \\
\text { the instr }\end{array}$ \\
\hline G1-1 & 0,63449 & 0,6221 & 0,4886 & 0,5498 & 0,4881 & 0,5759 & 0,4372 & 0,5607 & 0,5256 & 0,8307 & 0,3729 \\
\hline G1-2 & 0,886 & 0,8181 & 0,7529 & 0,8146 & 0,7991 & 0,8501 & 0,7711 & 0,8203 & 0,8206 & 0,9467 & 0,6801 \\
\hline G1-3 & 0,7545 & 0,6928 & 0,5615 & 0,6324 & 0,6056 & 0,6811 & 0,5675 & 0,6419 & 0,6403 & 0,8794 & 0,4728 \\
\hline G1-4 & 0,8895 & 0,8604 & 0,7658 & 0,8167 & 0,7863 & 0,8465 & 0,7495 & 0,8235 & 0,8143 & 0,977 & 0,6959 \\
\hline G2-1 & 0,8718 & 0,8043 & 0,7007 & 0,7635 & 0,7524 & 0,8122 & 0,7227 & 0,7714 & 0,7809 & 0,9398 & 0,6326 \\
\hline G2-2 & 0,8033 & 0,6971 & 0,5922 & 0,6552 & 0,6808 & 0,7281 & 0,6551 & 0,6531 & 0,702 & 0,8308 & 0,5404 \\
\hline G2-3 & 0,8333 & 0,6749 & 0,7139 & 0,7627 & 0,8384 & 0,8211 & 0,8681 & 0,7681 & 0,8341 & 0,6548 & 0,7333 \\
\hline G2-4 & 0,8895 & 0,8593 & 0,7633 & 0,8139 & 0,7846 & 0,8454 & 0,7489 & 0,8221 & 0,8134 & 0,9751 & 0,6935 \\
\hline
\end{tabular}

Table 6 Calculated coefficients of the test of confidence correlation

\begin{tabular}{|c|c|c|c|c|c|c|c|c|}
\hline Time & S1-G1-1 & S1-G1-3 & S1-G2-3 & S1-G2-1 & S2-G1-1 & S2-G1-3 & S2-G2-1 & S2-G2-3 \\
\hline 7 & 3,4387 & 3,8770 & 3,8760 & 3,7531 & 4,0611 & 4,4995 & 4,1888 & 4,3755 \\
\hline 8 & 3,4389 & 3,8772 & 3,8762 & 3,7532 & 4,0614 & 4,4997 & 4,1890 & 4,3757 \\
\hline 9 & 3,4412 & 3,8786 & 3,8786 & 3,7556 & 4,0635 & 4,5011 & 4,1892 & 4,3781 \\
\hline 9.30 & 3,4410 & 3,8784 & 3,8785 & 3,7558 & 4,0635 & 4,5010 & 4,1891 & 4,3783 \\
\hline 10 & 3,4409 & 3,8783 & 3,8783 & 3,7560 & 4,0634 & 4,5008 & 4,1890 & 4,3785 \\
\hline 10.30 & 3,4407 & 3,8785 & 3,8781 & 3,7558 & 4,0633 & 4,5012 & 4,1891 & 4,3782 \\
\hline 11 & 3,4405 & 3,8784 & 3,8777 & 3,7556 & 4,0630 & 4,5002 & 4,1892 & 4,3781 \\
\hline 12 & 3,4401 & 3,8787 & 3,8781 & 3,7560 & 4,0637 & 4,5013 & 4,1896 & 4,3785 \\
\hline
\end{tabular}

\section{CONCLUSION}

Measuring of displacements and deformations is a very demanding field of engineering. As with all major facilities, including bridges, interdisciplinary approach is required for the creation of an optimal program for result measuring, analysing and interpreting. The state-of-the-art methods and equipment provide a high level of accuracy and reliability of the results. The aim of the study in this paper was to determine the influence of external factors on the size of the displacement or height difference. Interpreting the size of the displacements without the knowledge of the basic external factor such as the temperature can devaluate obtained results. The result can show itself in an unrealistic displacements of the structure which can lead to misleading conclusions with serious consequences for the stability of the structure and its exploitation.

External impacts, especially temperature, are very important factors that influence the size of the movements in the vertical direction. There are several methods and procedures for elimination of meteorological effects. In this paper, the focus was on the effect of temperature on the final values. The analysis showed that it is realistic to expect dependence between the temperature and the point height, or the vertical displacement of the point, therefore this connection had to be studied. The link was checked through a statistical test. For this purpose, the temperature was measured with the contact probe in different places on the ground and a stochastic connection between the displacement and the temperature was found. The results indicate the dependence, which means that the temperature should be measured at different locations even during the measurement itself, and this should be taken into account in the final calculations. In addition, a connection between the vertical component and the temperature change has been calculated and proved with the calculated coefficients of correlation. To conclude, it is necessary to know that geodetic measurements of displacements and deformations are indispensable and are very much influenced by external factors.

\section{REFERENCES}

[1] Čvorović, M. (1986). Prilog metodologiji određivanja stabilnih točaka trigonometrijskih mreža pri pomjeranju tla i objekta, Dissertation, University of Beograd (in Serbian).

[2] Pelzer, H. (1985). Geodatische Netze in Landes und Inginiurvermessung II. Konrad Wittwer, Stuttgart (in German).

[3] Welsch, W. (1985). Geodatische Netze in Landes und Inginiurvermessung $V$. Konrad Wittwer, Stuttgart (in German).

[4] Bilajbegović, A. (1985). Deformacijska analiza, Zbornik radova: Geodezija u hidrogradnji, hidrografiji i hidrologiji, Split (in Croatian).

[5] Sabbagh, A. (1981). Instrumentelle Weiterentwicklung des geodetischen Alignements zur Erfassung von Deformationsvorgangen, Dissertation, Hannover (in German)

[6] Mihailović, K. (1986). Matematička obrada merenih veličina pri određivanju deformacija. Geodetski list, 4-6, 45-53 (in Serbian).

[7] Mihailović, K. \& Aleksić, I. (1994). Deformaciona analiza geodetskih mreža. University of Beograd, Gradevinski fakultet, Institut za geodezijo (in Serbian).

[8] Grundig, L. (1988). Datenverwaltungskonzept für typische aufgaben aus der Inginieurgeodesie, Dissertation. München (in German). 
[9] Caspary, W. F. (1988). Concepts of network and deformation analysis. Kensington, The University of New South Wales, School of Surveying.

[10] Rao, C. R. \& Mitra, S. K. (1971). Generalized Inverse of Matrices and its Applications. New York, London, Sydney, Toronto: John Wiley and Sons.

[11] Chen, Y. Q. (1983). Analysis of Deformation Surveys - A Generalized Approach, Dissertation. Fredericton, University of New Brunswick, Department of Geodesy and Geomatics Engineering.

[12] Chen, Y. Q., Chrzanowski, A., \& Secord J. M. (1990). A Strategy for the Analysis of the Stability of Reference Points in Deformation Surveys. CISM Journal ACSGC, 44(2), 141149

[13] Secord, M. J. (1985). Implementation of a Generalized Method for the Analysis of Deformation Surveys. University of New Brunswick, Department of Geodesy and Geomatics Engineering.

[14] Moeser, M., Mueller, G., Schlemmer, H., \& Werner, H. (2000). Handbuch Ingenieurgeodesie, Grundlagen, 3 ed., Wichmann Verlag, Heidelberg (in German).

[15] Heunecke, O. (1999). Die Genauichkeit und Zuverlaeishkeit von Inginiervermessungen nach DIN 18710, Teil 1: Inginierurvermessung in Bauwesen, DvW Schriftenreihe, 36, Verlag Konrad Wittwer, Stuttgart (in German).

[16] Benning, W. (2002). Statistik in Geodasie, geoinformation und Bauwesen, Wichmann Verlag, Heidelberg (in German).

[17] Chrzanowski, K. (2001). Non-Contact thermometry, Measurement Errors, Institute of Applied Optics, Warsaw, Poland

[18] Churchward, A. \& Sokol, Y. (1981). Prediction of Temperatures in Concrete Bridges. Journal of the Str. Div., ASCE, 107(51), 2163-2176.

[19] Kapović, Z. (1993). Prilog određivanju pomaka i deformacija mostova s posebnim osvrtkom na temperaturne utjecaje, Dissertation, University of Zagreb (in Croatian).

[20] Petz, B. (1964). Osnovne statističke metode, Zagreb (in Croatian).

\section{Contact information:}

\section{Boštjan KOVAČIČ, Asoc. Prof. PhD}

(Corresponding author)

University of Maribor,

Faculty of Civil Engineering, Transportation Engineering and Architecture

Smetanova ulica 17, 2000 Maribor, Slovenia

bostjan.kovacic@um.si

\section{Nenad GUBELJAK, Prof. PhD.}

University of Maribor,

Faculty of Mechanical Engineering,

Smetanova ulica 17, 2000 Maribor, Slovenia

nenad.gubeljak@um.si

Samo LUBEJ, Asoc. Prof. PhD

University of Maribor,

Faculty of Civil Engineering, Transportation Engineering and Architecture,

Smetanova ulica 17, 2000 Maribor, Slovenia

samo.lubej@um.si 